\title{
Residual effects of esmirtazapine on actual driving performance: overall findings and an exploratory analysis into the role of CYP2D6 phenotype
}

\author{
Johannes G. Ramaekers • Silke Conen • \\ Pieter Jan de Kam • Sabine Braat • Pierre Peeters • \\ Eef L. Theunissen • Neely Ivgy-may
}

Received: 25 October 2010 / Accepted: 8 December 2010 /Published online: 19 January 2011

(C) The Author(s) 2011. This article is published with open access at Springerlink.com

\begin{abstract}
Introduction Esmirtazapine is evaluated as a novel drug for treatment of insomnia.

Purpose The present study was designed to assess residual effects of single and repeated doses of esmirtazapine 1.5 and $4.5 \mathrm{mg}$ on actual driving in 32 healthy volunteers in a doubleblind, placebo-controlled study. Treatment with single doses of zopiclone $7.5 \mathrm{mg}$ was included as active control.

Methods Treatments were administered in the evening. Driving performance was assessed in the morning, $11 \mathrm{~h}$ after drug intake, in a standardized on-the-road highway driving test. The primary study parameter was standard deviation of lateral position (SDLP), a measure of "weaving". All subjects were subjected to CYP2D6 phenotyping in order to distinguish poor metabolizers from extensive metabolizers of esmirtazapine.

Results Overall, esmirtazapine $1.5 \mathrm{mg}$ did not produce any clinically relevant change in SDLP after single and repeated dosing. Driving impairment, i.e., a rise in SDLP, did occur after a single-dose administration of esmirtazapine $4.5 \mathrm{mg}$ but was resolved after repeated doses. Acute driving impairment was more pronounced after both doses of esmirtazapine in a
\end{abstract}

This trial has been registered at ClinicalTrials.gov as NCT00798395 http:// www.clinicaltrials.gov/ct2/show/NCT00798395?term=21105\&rank=1

J. G. Ramaekers $(\bowtie) \cdot$ S. Conen $\cdot$ E. L. Theunissen

Department of Neuropsychology and Psychopharmacology,

Faculty of Psychology and Neuroscience, Maastricht University,

Maastricht, The Netherlands

e-mail: j.ramaekers@maastrichtuniversity.nl

P. J. de Kam $\cdot$ S. Braat $\cdot$ P. Peeters

MSD,

Oss, The Netherlands

N. Ivgy-may

Merck \& Co.,

Summit, NJ, USA select group of poor metabolizers $(N=7)$. A single-dose zopiclone $7.5 \mathrm{mg}$ also increased SDLP as expected.

Conclusion It is concluded that single and repeated doses of $1.5 \mathrm{mg}$ esmirtazapine are generally not associated with residual impairment. Single-dose administration of $4.5 \mathrm{mg}$ esmirtazapine was associated with residual impairment that generally resolved after repeated administration. Exploratory analysis in a small group of poor CYP 2D6 metabolizers suggested that these subjects are more sensitive to the impairing effects of esmirtazapine on car driving.

Keywords Hypnotics · H1 antagonism · Driving ·

Cognition · CYP2D6 phenotype

\section{Introduction}

Esmirtazapine maleate (Org 50081) is the maleate salt of the $\mathrm{S}(+)$-enantiomer of the racemic drug mirtazapine. Racemic mirtazapine is marketed for the treatment of major depressive disorder. Mirtazapine is a close analog of its predecessor mianserin that also has been marketed for major depressive disorder. Esmirtazapine and mirtazapine bind to presynaptic $\alpha_{2}$ receptors as well as to postsynaptic $5 \mathrm{HT}_{2}$ and $\mathrm{H}_{1}$ receptors where they act as antagonists of the endogeneous ligands (de Boer and Ruigt 1995b; Pinder and van Delft 1983); however, compared with mirtazapine and R-mirtazapine, esmirtazapine has higher affinity to $5-\mathrm{HT}_{2}$ receptors and low affinity to the $5-\mathrm{HT}_{3}$ receptors and to the muscarinic receptors (de Boer et al. 1988; Kooyman et al. 1994). Esmirtazapine is under development for the treatment of primary insomnia and hot flushes.

Antidepressants such as mirtazapine and mianserin are well known for their sedative properties (Biswas et al. 
2003; Pinder and van Delft 1983). A range of studies have demonstrated that these drugs produce subjective fatigue and sleepiness and impair psychomotor function, cognition, and actual driving performance after acute dosing and to a lesser degree as well as after repeated dosing (Curran et al. 1986; Mattila et al. 1989; Ramaekers 2003; Ramaekers et al. 1998; 1992; Ridout et al. 2003; Wingen et al. 2005; 2006). Several studies have demonstrated that mirtazapine increases sleep efficiency, total sleep time, and slow wave sleep in patients with major depressive disorder and in healthy subjects (Anttila and Leinonen 2001; Radhakishun et al. 2000; Ruigt et al. 1990; Schmid et al. 2006; Winokur et al. 2000). Most of mirtazapine's abilities to produce daytime sedation comes from $\mathrm{H}_{1}$ blockade which is known to reduce arousal state in humans. Mirtazapine's action at the $5-\mathrm{HT}_{2 \mathrm{~A}}$ receptor may also contribute to its sedative effect; however, antagonism at the $5-\mathrm{HT}_{2 \mathrm{~A}}$ receptor is not thought to be responsible for the residual sedative effects seen following nighttime administration of mirtazapine. In clinical practice, antidepressant drugs with $\mathrm{H}_{1}$ antagonistic properties such as mirtazapine have been frequently used for the treatment of insomnia comorbid with various psychiatric disorders (Mayers and Baldwin 2005; Stahl 2008). Likewise, $H_{1}$ antagonists such as antihistamines are commonly sold over the counter as hypnotic drugs to treat insomnia because of their sleep-inducing propensities (Stahl 2008).

Mirtazapine and mianserin clearly have $\mathrm{H}_{1}$ antagonism as their most potent pharmacological property. Yet both drugs are dosed (i.e., $30 \mathrm{mg}$ or more) far above the minimum dose needed to obtain maximal binding to $\mathrm{H}_{1}$ receptors, in order to achieve sufficient serotonergic and noradrenergic action that is required for an antidepressant response. Mirtazapine has a $>100$-fold higher potency for the $\mathrm{H}_{1}$ receptor than for the $5 \mathrm{HT}_{3}$ and $\alpha_{2}$ receptors, and a tenfold higher potency for $5 \mathrm{HT}_{2}$ (De Boer and Ruigt 1995a; Stahl 2008). For esmirtazapine, it is postulated that the action on sleep is mediated via antagonism of both, the $\mathrm{H}_{1}$ and the $5-\mathrm{HT}_{2 \mathrm{~A}}$ receptors. The affinity of esmirtazapine to both receptors is high. Considering the action of these drugs on the $\mathrm{H}_{1}$ and $5 \mathrm{HT}_{2}$ receptor alone, sleep-promoting doses of these drugs can be far lower than the regular doses prescribed to treat depression. Effective sleep-promoting doses of esmirtazapine are expected to range between 1.5 and $4.5 \mathrm{mg}$. The possibility of developing esmirtazapine as a drug for treatment of insomnia however also raises the issue of residual daytime drowsiness and driving impairment since esmirtazapine elimination half-life is long (i.e., $>20 \mathrm{~h}$ ).

The effects of $\mathrm{H}_{1}$ antagonism by mianserin and mirtazapine on actual driving performance has been assessed by means of a standardized road-tracking task in previous studies (Ramaekers 2003; Wingen et al. 2005). Acute, daytime doses of mianserin $10 \mathrm{mg}$ t.i.d. produced elevations in standard deviation of lateral position (SDLP) during on-the-road driving that were equivalent to the effects of a blood alcohol concentration (BAC) $>1.0 \mathrm{mg} / \mathrm{ml}$ in the same driving test. After sub-chronic dosing, the impairing effects of mianserin reduced in magnitude but were still comparable to a blood alcohol concentration between 0.5 and $0.8 \mathrm{mg} / \mathrm{ml}$. The impairing effects of mianserin $(30-60 \mathrm{mg}$ ) on daytime SDLP however where much less (i.e., comparable to a $\mathrm{BAC}<0.05 \mathrm{mg} / \mathrm{ml}$ ) when the drug was administered in the evening, even though blood mianserin concentrations during driving after nocturnal and daytime doses were comparable (Ramaekers et al. 1998). Likewise, mirtazapine $15-30 \mathrm{mg}$ also produced mild residual driving impairment when administered as a nocturnal dose. Single doses of mirtazapine 15 and $30 \mathrm{mg}$ produced elevations in SDLP that were comparable to BACs of 0.5 and $0.8 \mathrm{mg} / \mathrm{ml}$. However, mirtazapine no longer produced any clinically relevant changes in driving performance after 1 or 2 weeks of repeated dosing.

The effect of $5 \mathrm{HT}_{2 \mathrm{~A} / 2 \mathrm{C}}$ antagonism on actual driving has been previously assessed in a study by van Laar et al. (2001). That study demonstrated that single and repeated doses of ritanserin $5 \mathrm{mg}$ b.i.d. increased nocturnal slow wave sleep, but failed to affect driving performance and sleepiness during daytime. This finding supports the present notion that residual impairment from esmirtazapine, if any at all, is more likely to arise from $\mathrm{H}_{1}$ blockade than from $5 \mathrm{HT}_{2}$ blockade.

The present study was designed to assess the effects of low, nocturnal doses of esmirtazapine on the next-day actual driving of healthy volunteers as assessed in a standardized on-the-road driving test and in laboratory performance tasks. Esmirtazapine is metabolized through CYP2D6 and its clearance is twice as low in poor metabolizers as compared to extensive metabolizers (Brockmoller et al. 2007). In the design phase, it was decided to select a representative population for this study, without restrictions on CYP2D metabolizer status. This allowed for an additional "post hoc" explorative analysis on the effects of esmirtazapine on actual driving performance for poor and extensive metabolizers as determined by cytochrome P450 2D6 (CYP2D6) phenotyping.

\section{Methods}

\section{Subjects}

Thirty-two healthy subjects, 16 men and 16 women, mean (SD) age $=33$ (9) years, were recruited by advertisement in local newspapers. Subjects were screened by a telephone interview and a health questionnaire, and all underwent a medical examination (including a standard 12-lead electro- 
cardiogram, blood hematology and chemistry, urinalysis, and drug and pregnancy screening). Selection was based on the following inclusion criteria: possession of a valid driving license for more than 3 years, driving experience of $>5,000 \mathrm{~km}$ per year on average, normal binocular visual acuity corrected or uncorrected, willingness to use doublebarrier method of birth control, body mass index of 18 to $30 \mathrm{~kg} / \mathrm{m}^{2}$ and written informed consent.

Subjects who met one or more of the following criteria were excluded from the study: history or present evidence of a serious illness such as renal, hepatic, cardiovascular, pulmonary, endocrine, neurologic or psychiatric, hematologic, or gastrointestinal diseases; insomnia or other sleep disorders; pregnancy (as determined at screening) or breastfeeding; known hypersensitivity to medicinal drugs; treatment with an investigational drug within 3 months prior to screening; use of medicines (except oral contraceptives and paracetamol); excessive smoking (more than five cigarettes a day); night work or rotation shift work, overconsumption of alcohol (more than 2 units per day) or caffeine (more than five cups of regular coffee a day); positive result of urine drug screening at the screening visit for alcohol and/or drug of abuse.

The study was approved by the standing Medical Ethics Committee of Maastricht University and was carried out in compliance with the current revision of the Declaration of Helsinki, International Conference on Harmonization guideline for Good Clinical Practice.

\section{Design and treatments}

The study was conducted according to a randomized, double-blind, placebo-controlled, four-way crossover design. Treatments were administered in separate 7-day series, and treatment orders were balanced following a Williams design and assigned by a predetermined randomization schedule, stratified by gender. The following treatment conditions were defined: nocturnal doses of $1.5 \mathrm{mg}$ esmirtazapine on day 1-7; nocturnal doses of $4.5 \mathrm{mg}$ esmirtazapine on day 1-7; nocturnal doses of placebo on day 1-7; and nocturnal doses of placebo on day 1-6 and zopiclone $7.5 \mathrm{mg}$ on day 7 . The zopiclone treatment was included to serve as an active control and to demonstrate (assay) sensitivity of the driving test to residual drug effects. Zopiclone $7.5 \mathrm{mg}$ has repeatedly been shown to produce residual driving impairment the in standardized highway driving test (Vermeeren 2004).

During days 1-7 of all treatment periods, trial medication was taken by the subjects at their homes. Subjects recorded the time of administration in a diary. On days 2-6, trial medication was taken in the evening, within $30 \mathrm{~min}$ before going to bed. On day 1 and 7, trial medication was administered under supervision of a research associate at a fixed time of drug administration (i.e., 2130 hours). Subjects went to bed within $1 \mathrm{~h}$ after drug intake. The washout period between treatments was at least 7 days.

Driving tests and cognitive tests were administered at days 2 and 8 of treatment, with the driving test starting on average $11 \mathrm{~h}$ after drug intake (range, between 10 and $11.5 \mathrm{~h}$ ) and the cognitive and psychomotor tests starting approximately $13 \mathrm{~h}$ after drug intake. All subjects scored negative on drug and alcohol screens at all times that were conducted on test days prior to performance testing. A blood sample was taken between the driving test and the cognitive psychomotor performance tests. Subjects were instructed to refrain from alcohol use $24 \mathrm{~h}$ prior to and throughout treatment periods. A summary of treatment and performance assessments schedule on day 2 and 8 is given in Fig. 1.

\section{Performance tests}

Driving and psychometric tests were trained during two separate training sessions prior to the first treatment condition in order to minimize learning effects.

\section{Highway driving test}

In the highway driving test (O'Hanlon 1984; O'Hanlon et al. 1982), the subjects operate a specially instrumented vehicle for about $1 \mathrm{~h}$ over a $100 \mathrm{~km}$ primary highway circuit while maintaining a constant speed $(95 \mathrm{~km} / \mathrm{h})$ and a steady lateral position between the delineated boundaries of the right (slower) traffic lane. An electro-optical device mounted at the rear back of the car continuously measures lateral distance separating the vehicle and the left lane-line. This signal is digitized at a rate of $4 \mathrm{~Hz}$ and stored on an onboard computer disk file for later editing analysis. The off-line editing routine involves removal of all data segments that reveal signal loss, disturbance or occurrence of passing maneuvers. The edited dataset is then used to calculate means and variances for lateral position. SDLP is taken as the primary outcome variable. SDLP is a measure of road tracking error, in practical terms, a composite index of allowed weaving, swerving, and overcorrecting. The highway driving test has been calibrated in a manner allowing expression of any sedative drug effect in terms of the BAC required to achieve the equivalent level of driving impairment (Louwerens et al. 1987). The alcohol calibration curve demonstrates that drinkers' mean SDLP rises exponentially with BAC. Results from the alcohol calibration study can be used for describing drugs' effects on SDLP in terms of respective BAC equivalencies. The change in SDLP at a BAC of $0.5 \mathrm{mg} / \mathrm{ml}$ has been used as a criterion level to quantify drug effects. Any drug-induced changes in SDLP that exceed this criterion value are defined as clinically relevant impairing drug effect in the present study. 


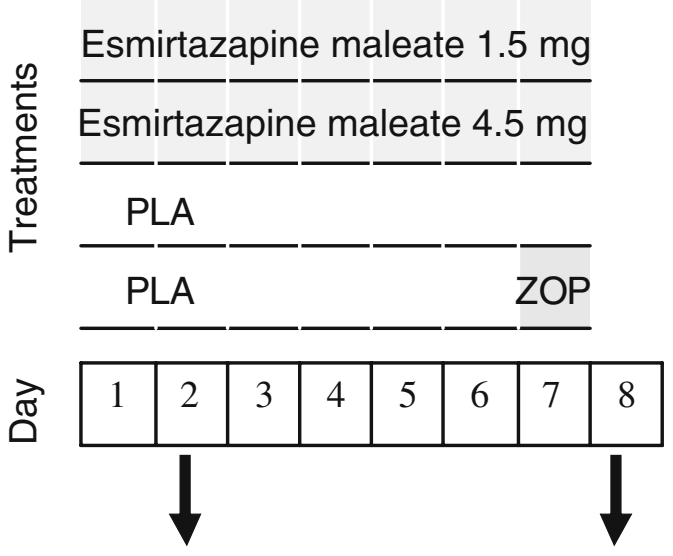

Highway driving, cognitive and psychomotor assessments

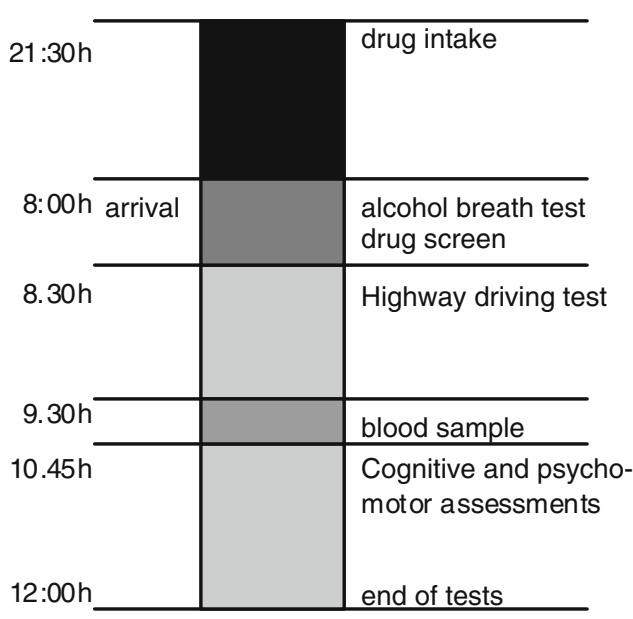

Fig. 1 Summary of treatments and activities schedule on days 2 and 8 in every treatment condition. ZOP zopiclone $7.5 \mathrm{mg}, P L A$ placebo

\section{Cognitive and psychomotor tests}

The word learning task is a verbal memory test for the assessment of immediate recall and delayed recall. Fifteen monosyllabic nouns sounded for $2 \mathrm{~s}$. At the end of the sequence the subject is asked to recall as many words as possible (recall-order unimportant). The number correct is scored as the first trial score. This procedure is repeated three times and the summed trial score is referred to as the immediate recall score (number). After a delay of at least $20 \mathrm{~min}$, the subject is again required to recall as many words as possible (without new presentation of the nouns). The number correct is referred to as the delayed recall score (number). The word learning task was conducted during the highway driving test.

The stop-signal task requires subjects to make quick key responses to visually presented go signals and to inhibit any response when a visual stop signal is suddenly presented. The current test is adapted from an earlier version of Fillmore et al. (2002) and has been validated for showing stimulant and sedative drug effects (Ramaekers et al. 2006; Ramaekers and Kuypers 2006). The go signals were four $1.5-\mathrm{cm}$ letters $(\mathrm{ABCD})$ presented one at a time in the center of a computer screen. Subjects were required to respond to each letter as quickly as possible by pressing one of two response buttons. One button is pressed to indicate that " $\mathrm{A}$ " or " $\mathrm{C}$ " appeared and the other to indicate "B" or " $\mathrm{D}$ ". Letters were displayed for $500 \mathrm{~ms}$ and the computer screen was blank for $1.5-\mathrm{s}$ interstimulus interval before the next letter was displayed. This provides a period of $2 \mathrm{~s}$ during which the subject can respond to a letter. A single test consists of 176 trials in which each of the four-letter stimuli is presented equally often. A stop signal occurs in 48 trials during a test. The stop signal consists of visual cue, i.e., "**, that appears in one of the four corners of the screen. Subjects are required to withhold any response when a stop-signal is presented. The task lasts about $10 \mathrm{~min}$. Primary dependant variable is reaction time in stop trials (millisecond). Secondary parameters are response time (millisecond) in go trials and number of errors in go and stop trials (number).

The critical tracking task measures the subject's ability to control a displayed error signal in a first-order compensatory tracking task. Error is displayed as a horizontal deviation of a cursor from the midpoint on a horizontal, linear scale. Compensatory joystick movements null the error by returning the cursor to the midpoint. The frequency at which the subject loses the control is the critical frequency or $\lambda_{c}$ (radians per second). The test includes five trials of which the lowest and the highest score are removed; the average of the remaining scores is taken as the final score.

The divided attention task measures the subject's ability to divide attention between two tasks performed simultaneously. The primary task consist of tracking task as described above but at a constant level of difficulty set at $50 \%$ of the subject's maximum capacity. Tracking error is measured as the difference in millimeters between the position of the cursor and the midpoint of the scale. In the secondary task, the subject monitors a central display upon which single digits are presented at 1-s intervals. The occurrence of the digit " 2 " is a signal for the subject to remove the foot from a pedal as rapidly as possible. Interstimulus interval varies between 1 and 2 s. Mean absolute tracking error (millimeters) and Average Reaction Time (milliseconds) are the main performance measures.

\section{CYP2D6 phenotyping}

CYP2D6 characterization was performed prior to the first intake of trial medication in period 1 of the four-period 
crossover sequences. Subjects received one tablet of dextromethorphan $30 \mathrm{mg}$ together with $200 \mathrm{ml}$ water before bedtime. Subjects had to empty their bladder pre-dose. Subsequently, subjects' morning urine was collected in containers. The excretion ratio dextromethorphan/dextrorphan in urine determined the CYP2D6 metabolizer status of each subject. Subjects with an excretion ratio $\geq 0.3$ were characterized as poor metabolizers, subject whose excretion ratio $<0.3$ were characterized as extensive metabolizers. In total, $7(22 \%)$ subjects were classified as poor metabolizers (4 males/3 females) and 25 (78\%) subjects (12 males/13 females) as extensive metabolizers.

\section{Pharmacokinetics}

Blood samples $(5 \mathrm{ml})$ for esmirtazapine determinations were collected at the time points indicated in Fig. 1 and processed to plasma. Plasma samples were stored and frozen at $-20^{\circ} \mathrm{C}$ and later analyzed by LC-MS-MS. The lower limit of quantification is $0.02 \mathrm{ng} / \mathrm{ml}$.

\section{Statistics}

Sample size was based on a power calculation for noninferiority between esmirtazapine $4.5 \mathrm{mg}$ and placebo after multiple-dose administration with respect to actual driving performance as assessed by means of SDLP. Given a mean population standard deviation of $4.0 \mathrm{~cm}$, a mean difference in SDLP of $0.5 \mathrm{~cm}$ between multiple dose esmirtazapine $4.5 \mathrm{mg}$ and placebo, a test-retest $\geq 0.70$ and a noninferiority margin of $2.5 \mathrm{~cm}$, a sample size of 26 subjects is sufficient to demonstrate non-inferiority with a power of at least $90 \%$ and a two-sided $\alpha$-level of 0.05 . This sample size is also sufficiently large (i.e., power of at least $90 \%$ ) for detecting a clinically relevant effect of $2.5-\mathrm{cm}$ mean difference in SDLP between single-dose zopiclone $7.5 \mathrm{mg}$ and placebo to demonstrate assay-sensitivity. Taking into account the possibility of drop-outs the total sample size was set at $N=32$ or 8 subjects per treatment crossover sequence stratified by gender (i.e., four males and four females).

Estimation of differences in SDLP between poor and extensive CYP 2D6 metabolizers was not pre-specified as an objective of this study, and hence, the study was not powered for these subgroup analyses. Therefore, the results of these subgroups have to be interpreted in the perspective of the explorative character of these analyses.

Statistical analyses of the driving, cognition, and psychomotor function parameters was done using a mixed model including fixed factors for treatment, period, treatment sequence, gender, day, and treatment by day interaction. Kenward-Roger approximation was used to estimate denominator degrees of freedom. Subject was included as a random factor and day as a repeated factor. No fixed structure was assumed for the repeated measures (co)variance. Least-squares estimates of contrasts to placebo and two-sided $95 \%$ CI were obtained from this model for single-doses and multiple-doses treatment separately. Efficacy analyses included all subjects randomly assigned to treatment sequence, treated, for whom results from at least one driving test during treatment was available, and without any pre-defined protocol violations that might impact efficacy conclusions. Adverse events (AEs) were coded using the MedDRA dictionary. AEs occurring during the washout period were assigned to the treatment taken during the preceding treatment period. AEs occurring before intake of zopiclone $7.5 \mathrm{mg}$ in the placebo-zopiclone treatment period were assigned to placebo. AE tabulations included the number and percentage of subjects with at least one AE by MedDRA preferred term. Safety analyses included all subjects that were randomly assigned to treatment sequence and treated. For the efficacy evaluation, all complete and incomplete data were included in the statistical analyses (i.e. no imputation was performed for missing data). Statistical analyses were performed using $\mathrm{SAS}^{\circledR}$ version 9.1.3.

The aim of the present study was to compare next-day driving performance, as expressed by the SDLP, of esmirtazapine with placebo. The study was designed as a non-inferiority trial, with evaluation of SDLP effects in relation to a reference BAC concentration. For SDLP, noninferiority between treatments was concluded if the upper limit of the two-sided $95 \%$ confidence interval (CI) of the mean difference in SDLP between drug and placebo below $2.5 \mathrm{~cm}$. The upper limit of the non-inferiority margin is chosen such that it excludes with high certainty a drug effect $>$ BAC $0.5 \mathrm{mg} / \mathrm{ml}$, which is considered clinically relevant.

\section{Results}

A total of 32 subjects entered the study. Twenty-nine subjects completed all four treatment periods whereas, three subjects prematurely discontinued. Two subjects dropped out during treatment with esmirtazapine $4.5 \mathrm{mg}$ due to adverse events. In one case, the subject complained of asthenia, fatigue, and muscular weakness starting $25 \mathrm{~min}$ after intake of the first dose and decided to stop study participation. This subject was a poor CYP 2D6 metabolizer and the adverse events were considered related to study treatment. The other subject was discontinued after being diagnosed with breast cancer. In the judgment of the medical supervisor, this serious adverse event was not likely to be related to study treatments. Another subject dropped out between the third and fourth treatment period because she could no longer adhere to study restrictions relating to alcohol intake. Median compliance to trial 
medication was $100 \%$ after single doses and multiple doses of all treatments.

Highway driving, cognition, and psychomotor function

Overall, mean (SD) SDLP after single doses of esmirtazapine $1.5 \mathrm{mg}$, esmirtazapine $4.5 \mathrm{mg}$, zopiclone $7.5 \mathrm{mg}$ and placebo were 19.6 (3.6), 20.3 (3.4), 20.6 (3.3), and 18.3 (2.9), respectively. Mean (SD) SDLP after repeated doses of esmirtazapine $1.5 \mathrm{mg}$, esmirtazapine $4.5 \mathrm{mg}$ and placebo were 19.8 (3.6), 19.8 (3.8), and 19.5 (3.3), respectively.

Assay-sensitivity was clearly demonstrated as shown by the inferiority of zopiclone $7.5 \mathrm{mg}$ to placebo: i.e., the lower limit of the $95 \%$ CI was above zero. Moreover, the estimated mean difference in SDLP between zopiclone and placebo was larger than the non-inferiority margin of $2.5 \mathrm{~cm}$, with an upper limit of the $95 \%$ CI of $3.6 \mathrm{~cm}$.

The primary endpoint, mean difference in SDLP after multiple dose treatment of esmirtazapine $4.5 \mathrm{mg}$ with placebo, clearly showed non-inferiority, i.e., the upper limit of the $95 \%$ CI of the estimated mean difference in SDLP of multiple-dose esmirtazapine $4.5 \mathrm{mg}$ vs. placebo was lower than the non-inferiority margin of $2.5 \mathrm{~cm}$. In agreement with this finding, the estimated mean difference in SDLP following single- and multiple-dose treatment of esmirtazapine $1.5 \mathrm{mg}$ as compared to placebo, also showed noninferiority. However, following single doses of esmirtzapine $4.5 \mathrm{mg}$, non-inferiority to placebo could not be demonstrated; the upper limit of the $95 \%$ CI of SDLP $(3.2 \mathrm{~cm})$ exceeded the non-inferiority margin of $2.5 \mathrm{~cm}$. The mean (95\% CI) differences from placebo in SDLP values for all treatment conditions are shown in Fig. 2.

In total, 7 (22\%) subjects were classified as poor metabolizers and 25 (78\%) subjects as extensive metabolizers. The explorative analysis on poor metabolizers $(N=7)$ indicated inferiority compared to placebo following singledose administration of 1.5 and $4.5 \mathrm{mg}$ esmirtazapine, as the upper limits of the $95 \%$ CI of SDLP difference vs. placebo exceeded the non-inferiority margin and the lower limits were above zero. After multiple doses, non-inferiority was demonstrated for the lower dose of esmirtazapine, but not for the higher dose.

The analysis of the data subset from extensive metabolizers $(N=25)$ yielded results similar to those obtained from the data of the entire study population. In extensive metabolizers, non-inferiority was shown for the mean difference vs. placebo in SDLP after a single dose of esmirtazapine $1.5 \mathrm{mg}$ and after multiple doses of esmirtazapine 1.5 and $4.5 \mathrm{mg}$. Non-inferiority vs. placebo was not shown for SDLP after a single dose of esmirtazapine $4.5 \mathrm{mg}$. Mean $(95 \% \mathrm{CI})$ SDLP in poor and extensive metabolizers is shown in Fig. 3.

When comparing poor and extensive metabolizers, there were no statistically significant differences between the two metabolizer groups for any of the four treatment comparisons for interest (i.e., for the comparison of esmirtazapine single dose of $1.5 \mathrm{mg}$ to placebo $(p=0.43)$, single dose of $4.5 \mathrm{mg}$ to placebo $(p=0.09)$, multiple dose of $1.5 \mathrm{mg}$ to placebo $(p=0.26)$, and multiple dose of $4.5 \mathrm{mg}$ to placebo $(p=0.29))$. It should be noted that the study was not powered to draw conclusions on non-inferiority within or between subgroups.

Laboratory test demonstrated that the effects of zopiclone on cognition and psychomotor function were not shown to be statistically different from placebo. In general, the cognitive tests results for mirtazapine did not show clear dose-response relationship or major differences between the results following single-dose and multiple-doses administration. Moreover, esmirtazapine did not show statistical differences from placebo for most laboratory measures, except for tracking error in the divided-attention task. The performance on this task was statistically significantly worse than placebo after single and multiple doses of $1.5 \mathrm{mg}$ and single doses of $4.5 \mathrm{mg}$ esmirtazapine, but not after multiple dose of $4.5 \mathrm{mg}$ esmirtazapine. Following esmirtazapine $1.5 \mathrm{mg}$ single doses only, delayed recall in the word learning task and response time in the divided attention task also showed a statistically significant
Fig. 2 Mean $(95 \%$ CI $)$ SDLP difference from placebo after single doses of esmirtazapine $(E S M)$ and zopiclone $(Z O P)$ and after multiple doses of ESM. Single asterisk, non-inferiority not shown, upper bound of the $95 \% \mathrm{CI}$ is above the noninferiority margin of $2.5 \mathrm{~cm}$

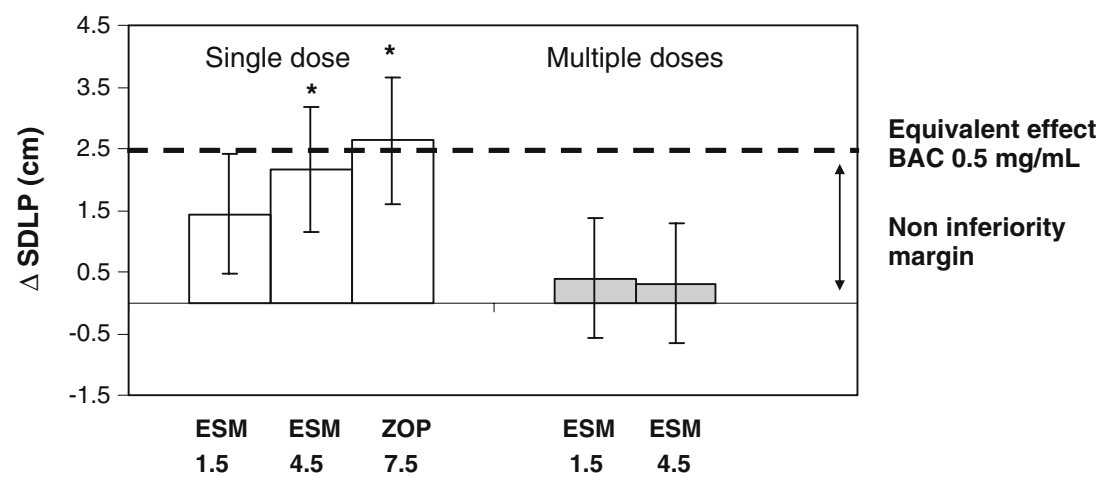


Fig. 3 Mean $(95 \%$ CI $)$ SDLP difference from placebo after single doses of esmirtazapine $(E S M)$ and after multiple doses of ESM in poor $(N=7)$ and extensive metabolizers $(N=25)$. Single asterisk, non-inferiority not shown, upper bound of the $95 \% \mathrm{CI}$ is above the noninferiority margin of $2.5 \mathrm{~cm}$

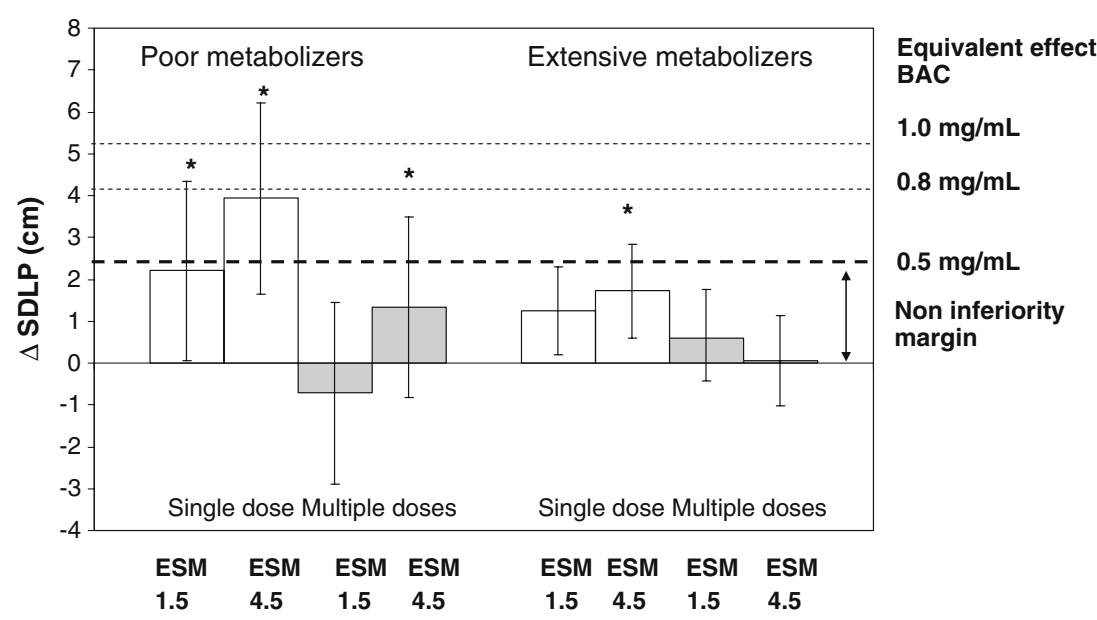

worsening compared with placebo. A summary of performance on cognitive and psychomotor measures is given in Table 1.

\section{Pharmacokinetics}

A summary of mean (SD) and median esmirtazapine concentrations is given in Table 2. In general, mean and median esmirtazapine concentrations in poor metabolizers were about twice as high as those of extensive metabolizers.

\section{Adverse events}

Treatment of esmirtazapine for 7 days was generally safe and well tolerated. Overall, somnolence and fatigue were the most frequently reported adverse events. Somnolence was mainly experienced by subjects treated with esmirtazapine 1.5 or $4.5 \mathrm{mg}$. A summary of adverse events reported with incidence of at least $5 \%$ in any treatment during all treatments and during the first $24 \mathrm{~h}$ after first treatment dose is given in Table 3 and 4, respectively.

After single-dose administration, somnolence and fatigue were also the most frequently reported adverse events. Note that adverse events summarized under placebo were reported on two single-dose days (i.e., combining the first day of placebo in the zopiclone group and first day of placebo in the placebo group). Furthermore, while the single-dose safety evaluation of placebo and esmirtazapine refer to the first day of treatment, the single-dose zopiclone results refer to the seventh day of treatment., where subjects are less likely to report AEs (including drug-related AE) if these $\mathrm{AE}$ were already reported earlier during this treatment period while on placebo. As can be seen in Table 4, the overall frequency of adverse events as well as the frequencies of reported somnolence and fatigue while on zopiclone is lower than that reported while on placebo.

\section{Discussion}

Overall, non-inferiority vs. placebo was demonstrated for multiple doses of $1.5 \mathrm{mg}$ and multiple doses of $4.5 \mathrm{mg}$ esmirtazapine as compared to placebo. The results for these esmirtazapine doses indicated that the overall effects of esmirtazapine on car driving were mild and of no clinical relevance after 1 week of dosing. However, following a single dose of $4.5 \mathrm{mg}$ esmirtazapine, non-inferiority could not be demonstrated as compared to placebo. While the mean SDLP difference vs. placebo was somewhat lower than the effect observed with $0.05 \mathrm{BAC}$, the upper limit of the $95 \%$ CI exceeded the non-inferiority margin. Thus, a single dose of $4.5 \mathrm{mg}$ esmirtazapine produced a statistically and clinically significant driving impairment. After repeated administration for 1 week, both doses of esmirtazapine did not produce any residual impairment as is evident by the finding that the $95 \%$ CI of mean difference in SDLP vs. placebo always contained zero and its upper limit was well below the non-inferiority margin. The finding of driving impairment after single dose of $4.5 \mathrm{mg}$ but not after single doses of $1.5 \mathrm{mg}$ esmirtazapine suggests that the acute effect of esmirtazapine on driving impairment is dose dependent. This effect rapidly resolves after repeated administration.

Previous studies (O'Hanlon and Ramaekers 1995; Ramaekers 2003) on the effects of $H_{1}$ antagonists on actual driving performance have shown more pronounced effects on SDLP than those observed after esmirtazapine in the present study, however, the overall pattern was similar. Antidepressants with strong $\mathrm{H}_{1}$ antagonistic activity such as amitriptyline, imipramine, and doxepin all produced significant driving impairment after single doses administered during the day. Difference in SDLP from placebo after single doses of these sedating antidepressants were comparable to those seen in drivers conducting the same test with a blood alcohol concentration (BAC) of $0.8 \mathrm{mg} / \mathrm{ml}$ or higher. The impairing effects of sedating antidepressants 
Table 1 Mean (SD) difference from placebo and 95\% CI for cognitive and psychomotor measures in all treatments after single (s) and multiple (m) doses

\begin{tabular}{|c|c|c|c|c|c|c|}
\hline Parameter & Drug/dose & $N$ & Mean (SD) & Difference $^{\mathrm{a}}$ & $95 \% \mathrm{CI}^{\mathrm{a}}$ & Significance \\
\hline \multicolumn{7}{|l|}{ Word learning task } \\
\hline \multirow[t]{7}{*}{ Immediate recall score (number) } & PLA (s) & 31 & $26.3(4.8)$ & & & \\
\hline & ESM $1.5(s)$ & 29 & $24.4(5.3)$ & -1.7 & {$[-3.8,0.4]$} & \\
\hline & ESM $4.5(s)$ & 29 & $26.6(5.8)$ & 0.4 & {$[-1.2,2.1]$} & \\
\hline & $\mathrm{ZOP}(\mathrm{s})$ & 29 & $26.0(5.1)$ & -0.1 & {$[-2.0,1.8]$} & \\
\hline & PLA (m) & 28 & $27.0(5.7)$ & & & \\
\hline & ESM $1.5(\mathrm{~m})$ & 30 & $26.7(6.5)$ & 0.2 & {$[-2.3,2.6]$} & \\
\hline & ESM $4.5(\mathrm{~m})$ & 30 & $26.8(5.9)$ & -0.2 & {$[-2.7,2.3]$} & \\
\hline \multirow[t]{7}{*}{ Delayed recall score (number) } & PLA (s) & 31 & $9.3(2.9)$ & & & \multirow{7}{*}{$\mathrm{b}$} \\
\hline & ESM $1.5(\mathrm{~s})$ & 29 & $7.8(3.3)$ & -1.4 & {$[-2.5,-0.3]$} & \\
\hline & ESM $4.5(\mathrm{~s})$ & 29 & $8.6(3.6)$ & -0.7 & {$[-1.6,0.2]$} & \\
\hline & ZOP (s) & 28 & $8.7(3.0)$ & -0.6 & {$[-1.5,0.3]$} & \\
\hline & PLA (m) & 28 & $8.9(3.3)$ & & & \\
\hline & ESM $1.5(\mathrm{~m})$ & 30 & $9.4(3.5)$ & 0.7 & {$[-0.4,1.8]$} & \\
\hline & $\operatorname{ESM} 4.5(\mathrm{~m})$ & 29 & $9.3(3.1)$ & 0.6 & {$[-0.4,1.6]$} & \\
\hline \multicolumn{7}{|l|}{ Divided attention task } \\
\hline \multirow[t]{7}{*}{ Tracking error (mm) } & PLA (s) & 31 & $19.9(3.8)$ & & & \multirow{7}{*}{$\begin{array}{l}\mathrm{b} \\
\mathrm{b}\end{array}$} \\
\hline & ESM $1.5(\mathrm{~s})$ & 29 & $21.3(4.2)$ & 1.4 & {$[0.6,2.3]$} & \\
\hline & ESM $4.5(\mathrm{~s})$ & 31 & $21.8(4.3)$ & 2.0 & {$[0.9,3.1]$} & \\
\hline & $\mathrm{ZOP}(\mathrm{s})$ & 29 & $20.1(4.6)$ & 0.2 & {$[-0.9,1.3]$} & \\
\hline & PLA (m) & 30 & $20.1(4.5)$ & & & \\
\hline & ESM $1.5(\mathrm{~m})$ & 30 & $21.4(4.1)$ & 1.2 & {$[0.1,2.2]$} & \\
\hline & ESM $4.5(\mathrm{~m})$ & 30 & $21.1(4.6)$ & 0.9 & {$[-0.1,2.0]$} & \\
\hline \multirow[t]{7}{*}{ Response time (ms) } & $\operatorname{PLA}(\mathrm{s})$ & 31 & $1770(246)$ & & & \multirow{7}{*}{$\mathrm{b}$} \\
\hline & ESM $1.5(\mathrm{~s})$ & 29 & $1899(261)$ & 139 & {$[33,246]$} & \\
\hline & ESM $4.5(\mathrm{~s})$ & 31 & 1859 (247) & 95 & {$[-3,192]$} & \\
\hline & $\mathrm{ZOP}(\mathrm{s})$ & 29 & $1833(205)$ & 62 & {$[-33,157]$} & \\
\hline & PLA (m) & 30 & $1783(228)$ & & & \\
\hline & ESM $1.5(\mathrm{~m})$ & 30 & $1812(202)$ & 27 & {$[-50,105]$} & \\
\hline & ESM $4.5(\mathrm{~m})$ & 30 & $1811(211)$ & 30 & {$[-49,109]$} & \\
\hline \multicolumn{7}{|l|}{ Critical tracking task } \\
\hline \multirow[t]{7}{*}{ Critical frequency $(\mathrm{rad} / \mathrm{s})$} & PLA (s) & 31 & $3.43(0.62)$ & & & \\
\hline & ESM $1.5(\mathrm{~s})$ & 30 & $3.36(0.61)$ & -0.10 & {$[-0.22,0.02]$} & \\
\hline & ESM $4.5(s)$ & 32 & $3.29(0.68)$ & -0.15 & {$[-0.33,0.03]$} & \\
\hline & $\mathrm{ZOP}(\mathrm{s})$ & 30 & $3.38(0.79)$ & -0.05 & {$[-0.22,0.12]$} & \\
\hline & PLA (m) & 30 & $3.41(0.72)$ & & & \\
\hline & ESM $1.5(\mathrm{~m})$ & 30 & $3.44(0.62)$ & 0.02 & {$[-0.12,0.16]$} & \\
\hline & ESM $4.5(\mathrm{~m})$ & 30 & $3.34(0.70)$ & -0.07 & {$[-0.22,0.08]$} & \\
\hline \multicolumn{7}{|l|}{ Stop-signal task } \\
\hline \multirow[t]{7}{*}{ Stop reaction time $(\mathrm{ms})$} & PLA (s) & 31 & $288(48)$ & & & \\
\hline & ESM $1.5(s)$ & 30 & $292(46)$ & 4 & {$[-15,23]$} & \\
\hline & ESM $4.5(s)$ & 32 & $297(51)$ & 8 & {$[-13,30]$} & \\
\hline & $\mathrm{ZOP}(\mathrm{s})$ & 30 & $292(49)$ & 4 & {$[-15,23]$} & \\
\hline & PLA (m) & 30 & $285(45)$ & & & \\
\hline & ESM $1.5(\mathrm{~m})$ & 30 & $297(57)$ & 13 & {$[-11,36]$} & \\
\hline & ESM $4.5(\mathrm{~m})$ & 30 & $288(49)$ & 3 & {$[-18,24]$} & \\
\hline
\end{tabular}

${ }^{a}$ Least square mean differences and $95 \%$ CIs obtained from mixed model analyses

${ }^{\mathrm{b}}$ Statistically significantly different at $5 \%$ level 
Table 2 Mean (SD) and median esmirtazapine plasma concentrations (nanograms/millilter) in poor and extensive metabolizers

\begin{tabular}{|c|c|c|c|c|c|c|c|}
\hline \multirow{2}{*}{\multicolumn{2}{|c|}{ Esmirtazapine }} & \multirow{2}{*}{$\begin{array}{l}\text { Extensive metabolizers } \\
(N=25) \\
\text { Day } 2\end{array}$} & \multirow[b]{2}{*}{ Day 8} & \multirow{2}{*}{$\begin{array}{l}\text { Poor metabolizers } \\
(N=7) \\
\text { Day } 2\end{array}$} & \multirow[b]{2}{*}{ Day 8} & \multirow{2}{*}{$\begin{array}{l}\text { Overall } \\
(N=32)\end{array}$} & \multirow[b]{2}{*}{ Day 8} \\
\hline & & & & & & & \\
\hline \multirow[t]{2}{*}{$1.5 \mathrm{mg}$} & Mean (SD) & $0.53(1.02)$ & $0.54(0.42)$ & $0.67(0.27)$ & $0.97(0.70)$ & $0.56(0.91)$ & $0.63(0.51)$ \\
\hline & Median & 0.34 & 0.47 & 0.66 & 0.81 & 0.35 & 0.48 \\
\hline \multirow[t]{2}{*}{$4.5 \mathrm{mg}$} & Mean (SD) & $1.05(0.44)$ & $1.52(0.66)$ & $2.07(0.84)$ & $2.12(0.96)$ & $1.28(0.70)$ & $1.64(0.75)$ \\
\hline & Median & 0.92 & 1.29 & 1.80 & 2.53 & 1.10 & 1.38 \\
\hline
\end{tabular}

such as mirtazapine on next-day driving performance however were markedly lower when given in the evening. The impairing effects of antidepressants on driving were mostly present after single doses but disappeared after 1 week of repeated dosing due to tolerance (Ramaekers 2003). Likewise, single doses of antihistamines have been demonstrated to significantly increase SDLP in a doserelated manner (O'Hanlon and Ramaekers 1995). However, the impairing effects of antihistamines on actual driving also resolved after 4-7 days after repeated dosing. In the present study, a single dose of esmirtazapine $4.5 \mathrm{mg}$ also produced significant driving impairment, but the impairing effects rapidly resolved after 1 week of repeated dosing. The implications would be twofold. First, next-day driving need not be a priori contraindicated for esmirtazapine $1.5 \mathrm{mg}$ as overall it did not produce relevant driving impairment after single and repeated doses. Second, nextday driving is not advised for patients taking a higher dose of esmirtazapine (i.e., $4.5 \mathrm{mg}$ ), but only during treatment initiation or initially after dose increase.
However, while the overall effect of esmirtazapine on driving performance is limited and transient, some subjects may be more susceptible to drug effects on driving impairment. In the case of esmirtazapine, which is a substrate for CYP2D6, patients who are poor metabolizers of CYP2D6 may experience greater impairment. In general, CYP2D6 has high relevance in drug metabolism. CYP2D6 is involved in the metabolism of $20-25 \%$ of clinically used drugs and exhibits a clinically relevant gene polymorphism that modifies the pharmacokinetics in patients that are either poor or extensive metabolizers (Ingelman-Sundberg et al. 2007; Tomalik-Scharte et al. 2008). About $5-10 \%$ of the Caucasian populations are poor metabolizers of CYP2D6 substrates which may cause elevated substrate concentrations in blood of these individuals. In the present study, seven subjects $(22 \%)$ were phenotyped as poor metabolizers. Especially for $4.5 \mathrm{mg}$ esmirtazapine, mean and median plasma concentrations of esmirtazapine were about twice as high as the levels observed in extensive metabolizers. Poor metabolizers also appeared to be more

Table 3 Summary of adverse events with incidence of at least $5 \%$ in any treatment group

\begin{tabular}{lcccc}
\hline Adverse events & $\begin{array}{l}\text { Placebo } \\
(N=31)\end{array}$ & $\begin{array}{l}\text { Esmirtazapine } 1.5 \mathrm{mg} \\
(N=30) \\
n(\%)\end{array}$ & $\begin{array}{l}\text { Esmirtazapine } 4.5 \mathrm{mg} \\
(N=32) \\
n(\%)\end{array}$ & $\begin{array}{l}\text { Zopiclone } 7.5 \mathrm{mg} \\
(N=30) \\
(\%)\end{array}$ \\
\hline Fatigue & $11(35.5)$ & $12(40.0)$ & $9(28.1)$ & $3(10.0)$ \\
Somnolence & $1(3.2)$ & $9(30.0)$ & $10(31.3)$ & $1(3.3)$ \\
Headache & $2(6.5)$ & $4(13.3)$ & $1(3.1)$ & $1(3.1)$ \\
Poor quality sleep & $6(19.4)$ & $3(10.0)$ & $1(3.1)$ & $1(3.3)$ \\
Dysgeusia & $4(12.9)$ & $2(6.7)$ & $1(3.1)$ & $0(0.0)$ \\
Nasopharyngitis & $1(3.2)$ & $2(6.7)$ & $2(6.3)$ & $1(3.1)$ \\
Dizziness & $1(3.2)$ & $2(6.7)$ & $0(0.0)$ & $0(0.0)$ \\
Disturbance in attention & $1(3.2)$ & $2(6.7)$ & $0(0.0)$ & $0(0.0)$ \\
Oral herpes & $0(0.0)$ & $2(6.7)$ & $2(6.3)$ & $0(0.0)$ \\
Oropharyngeal pain & $0(0.0)$ & $2(6.7)$ & $1(3.1)$ & $0(0.0)$ \\
Dry mouth & $1(3.2)$ & $1(3.3)$ & $0(0.0)$ & $0(0.0)$ \\
Vomiting & $2(6.5)$ & $0(0.0)$ & $0(0.0)$ & \\
Irritability & $2(6.5)$ & & \\
\hline
\end{tabular}


Table 4 Summary of adverse events during the first $24 \mathrm{~h}$ after first drug intake only with an incidence of at least $5 \%$ in any treatment group

\begin{tabular}{|c|c|c|c|c|}
\hline Adverse events & $\begin{array}{l}\text { Placebo } \\
(N=31) \\
n(\%)\end{array}$ & $\begin{array}{l}\text { Esmirtazapine } \\
1.5 \mathrm{mg} \\
(N=30) \\
n(\%)\end{array}$ & $\begin{array}{l}\text { Esmirtazapine } \\
4.5 \mathrm{mg} \\
(N=32) \\
n(\%)\end{array}$ & $\begin{array}{l}\text { Zopiclone } \\
7.5 \mathrm{mg} \\
(N=30) \\
n(\%)\end{array}$ \\
\hline Fatigue & $6(19.4)$ & $10(33.3)$ & $9(28.1)$ & $2(6.7)$ \\
\hline Somnolence & $1(3.2)$ & $4(13.3)$ & $8(25.0)$ & $0(0.0)$ \\
\hline Dysgeusia & $3(9.7)$ & $2(6.7)$ & $1(3.1)$ & $1(3.3)$ \\
\hline Disturbance in attention & $0(0.0)$ & $2(6.7)$ & $1(3.1)$ & $0(0.0)$ \\
\hline Headache & $1(3.2)$ & $2(6.7)$ & $0(0.0)$ & $1(3.3)$ \\
\hline Poor quality sleep & $5(16.1)$ & $1(3.3)$ & $0(0.0)$ & $1(3.3)$ \\
\hline Irritability & $2(6.5)$ & $0(0.0)$ & $0(0.0)$ & $0(0.0)$ \\
\hline
\end{tabular}

sensitive to the impairing potential of esmirtazapine. Increments in SDLP were more pronounced than placebo after single doses of esmirtazapine 1.5 and $4.5 \mathrm{mg}$ in poor metabolizers. After a week of repeated dosing, the low dose of esmirtazapine no longer produced any relevant impairment in poor metabolizers. However, while the absolute effect on SDLP compared to placebo for poor metabolizers was still below the non-inferiority margin of $2.5 \mathrm{~cm}$, the highest dose still produced an increment in SDLP after 1 week of dosing, which may indicate that tolerance to impairing effects of esmirtazapine may not have been complete after 7 days of dosing. These findings support the notion that dose effects of esmirtapine on driving are closely related to the drug's concentration in plasma.

For the extensive metabolizers, the results were similar to those obtained in the main analysis. No relevant impairment was observed after single and multiple doses of esmirtazapine $1.5 \mathrm{mg}$, whereas esmirtazapine $4.5 \mathrm{mg}$ produced a small, but clinically relevant increase in SDLP only after the initial dose.

A limitation of this explorative analysis on poor metabolizers is $(N=7)$ is that the present study was not powered to demonstrate non-inferiority of esmirtazapine to placebo in this small number of subjects $(N=7)$. Small numbers of subjects lead to wider confidence intervals which increase the chance that upper limits of $95 \%$ confidence intervals exceed a pre-specified limit, hampering their interpretation. For example, CIs in poor metabolizers $(N=7)$ are about twice as wide as those in extensive metabolizers $(N=25)$. Consequently, one must be cautious when comparing the upper CI limit of the mean difference in SDLP with placebo in poor metabolizers to a preestablished alcohol equivalent, as the CI may actually become less wide with increasing subject numbers. Nonetheless, the results of the current analysis indicated more pronounced driving impairment in poor metabolizers after treatment with esmirtazapine. Although the exact magnitude of this driving impairment should be determined in a larger subject sample when comparing to alcohol criterion levels, these results are in line with the observation that esmirtazapine has a dose-dependent effect on driving performance, with impairment observed after a single dose of $4.5 \mathrm{mg}$ or higher. In subjects with higher exposure, such as CYP2D6 poor metabolizers, the effect on driving performance is therefore likely to be more pronounced and impairment may be experienced even with a lower dose. It should be noted that the CYP2D6 phenotype only accounts for some of the inter-individual variability observed in the driving performance. While an effect on performance by gender and age, for example, was not observed, other factors may still exist that significantly influence the subject's susceptibility to drug effect on car driving performance. Thus, the general implications of these findings with regards to clinical practice may result in a recommendation to start treatment with the lowest available dose until therapeutic effect and tolerability are evaluated. Esmirtazapine is being evaluated for the treatment of insomnia in the dose range of $1.5-4.5 \mathrm{mg}$. Given the acute effect of esmirtazapine at $4.5 \mathrm{mg}$ on driving performance, a $1.5 \mathrm{mg}$ /day starting dose of esmirtazapine treatment may be recommended until therapeutic effect and tolerance is evaluated and the need to increase the dose is confirmed.

It should be noted here that factors that influence variability in drug response in general and, specifically, in CYP2D6 phenotype do not just pertain to esmirtazapine. For example, CYP2D6 is the major route of metabolism for many sedative CNS drugs such as antidepressants, antipsychotics, opioids, and antihistamines (Ingelman-Sundberg et al. 2007). Previous studies on the effects of drugs on driving have never taken CYP2D6 genotype into account. These explorative results indicate that subjects with genetic CYP deviations (e.g., poor CYP 2D6 metabolizers) may be at higher risk to be exposed to higher levels of drugs or metabolites which have the potential to impair car driving. A distinction in poor and extensive metabolizers may be of particular importance when overall driving impairment levels in the general study population are mild. Based on such an overall finding, the conclusion would be that driving is not contraindicated for a particular substance. However, factors 
which influence exposure to these drugs need to be taken into account. Especially if there is a dose-response relationship between car driving performance and dose of the drug, then factors which increase exposure (e.g., gender, race, age, or P450 polymorphism) are likely to display more pronounced car driving impairment, which may reach levels of clinical relevance. Consequently, it should be recommended to always take factors likely to affect drug exposure and response, such as cytochrome $\mathrm{P} 450$ polymorphism into account when designing future studies on drug effects on driving.

In the present study, single doses of zopiclone $7.5 \mathrm{mg}$ increased SDLP by $2.6 \mathrm{~cm}$ over placebo. Mean difference in SDLP with placebo and its $95 \%$ CI upper limit exceeded the non-inferiority margin of $2.5 \mathrm{~cm}$ and the CI excluded zero. These data support findings from a number of previous studies that assessed the influence of zopiclone $7.5 \mathrm{mg}$ on SDLP as measured in the standardized highway driving test (Leufkens et al. 2009; Leufkens and Vermeeren 2009; Vermeeren 2004). All of these studies demonstrated that evening doses of zopiclone produced residual driving impairment in the morning. In all studies, the impairing effects of zopiclone $7.5 \mathrm{mg}$ were comparable to a BAC between 0.5 and $0.8 \mathrm{mg} / \mathrm{ml}$. In the present study, impairment after zopiclone (verum) confirmed the sensitivity of the highway driving test for sedative drug effects and confirmed previous warnings concerning driving (Leufkens et al. 2009; Leufkens and Vermeeren 2009; Vermeeren 2004).

Overall, low doses of esmirtazapine $(1.5 \mathrm{mg})$ did not produce any relevant driving impairment after single and repeated dosing. Driving impairment did occur after a higher single dose of emirtazapine $(4.5 \mathrm{mg})$ but resolved after repeated doses. The explorative results on the subgroup of poor metabolizers $(N=7)$ indicated more pronounced car driving impairment after both doses of esmirtazapine, but not on the subgroup of extensive metabolizers $(N=25)$. In these individuals, impairment appeared to persist after 7 days after administration of the highest dose.

Acknowledgment This study was sponsored by Schering-Plough, Oss, The Netherlands. Nick Ward is acknowledged for his pharmacological contribution to the manuscript.

Open Access This article is distributed under the terms of the Creative Commons Attribution Noncommercial License which permits any noncommercial use, distribution, and reproduction in any medium, provided the original author(s) and source are credited.

\section{References}

Anttila SA, Leinonen EV (2001) A review of the pharmacological and clinical profile of mirtazapine. CNS Drug Rev 7:249-264

Biswas PN, Wilton LV, Shakir SA (2003) The pharmacovigilance of mirtazapine: results of a prescription event monitoring study on 13554 patients in England. J Psychopharmacol 17:121-126
Brockmoller J, Meineke I, Kirchheiner J (2007) Pharmacokinetics of mirtazapine: enantioselective effects of the CYP2D6 ultra rapid metabolizer genotype and correlation with adverse effects. Clin Pharmacol Ther 81:699-707

Curran HV, Shine P, Lader M (1986) Effects of repeated doses of fluvoxamine, mianserin and placebo on memory and measures of sedation. Psychopharmacology (Berl) 89:360-363

De Boer T, Ruigt GSF (1995a) The selective alpha 2-adrenoceptor antagonist mirtazapine (Org 3770) enhances noradreniergic and 5HT1a mediated serotonergic neurotransmission. CNS Drugs 4:29-38

de Boer T, Ruigt GSF (1995b) The selective effects of mirtazapine on central noradrenergic and serotonergic neurotransmission. Int Clin Psychopharmacol 10(Suppl 4):19-23

de Boer TH, Maura G, Raiteri M, de Vos CJ, Wieringa J, Pinder RM (1988) Neurochemical and autonomic pharmacological profiles of the 6-aza-analogue of mianserin, Org 3770 and its enantiomers. Neuropharmacology 27:399-408

Fillmore MT, Rush CR, Hays L (2002) Acute effects of oral cocaine on inhibitory control of behavior in humans. Drug Alcohol Depend 67:157-167

Ingelman-Sundberg M, Sim SC, Gomez A, Rodriguez-Antona C (2007) Influence of cytochrome P450 polymorphisms on drug therapies: pharmacogenetic, pharmacoepigenetic and clinical aspects. Pharmacol Ther 116:496-526

Kooyman AR, Zwart R, Vanderheijden PM, Van Hooft JA, Vijverberg HP (1994) Interaction between enantiomers of mianserin and ORG3770 at 5-HT3 receptors in cultured mouse neuroblastoma cells. Neuropharmacology 33:501-507

Leufkens TR, Lund JS, Vermeeren A (2009) Highway driving performance and cognitive functioning the morning after bedtime and middle-of-the-night use of gaboxadol, zopiclone and zolpidem. J Sleep Res 18(4):387-96

Leufkens TR, Vermeeren A (2009) Highway driving in the elderly the morning after bedtime use of hypnotics: a comparison between temazepam $20 \mathrm{mg}$, zopiclone $7.5 \mathrm{mg}$, and placebo. J Clin Psychopharmacol 29:432-438

Louwerens JW, Gloerich ABM, de Vries G, Brookhuis KA, O'Hanlon JF (1987) The relationship between drivers' blood alcohol concentration (BAC) and actual driving performance during high speed travel. In: Noordzij PC, Roszbach R (eds) Alcohol, drugs and traffic saftey - T86. Elsevier, Amsterdam, pp 183-186

Mattila M, Mattila MJ, Vrijmoed-de Vries M, Kuitunen T (1989) Actions and interactions of psychotropic drugs on human performance and mood: single doses of ORG 3770, amitriptyline, and diazepam. Pharmacol Toxicol 65:81-88

Mayers AG, Baldwin DS (2005) Antidepressants and their effect on sleep. Hum Psychopharmacol 20:533-559

O'Hanlon JF (1984) Driving performance under the influence of drugs: rationale for, and application of, a new test. Br J Clin Pharmacol 18(Suppl 1):121S-129S

O'Hanlon JF, Haak TW, Blaauw GJ, Riemersma JB (1982) Diazepam impairs lateral position control in highway driving. Science 217:79-81

O'Hanlon JF, Ramaekers JG (1995) Antihistamine effects on actual driving performance in a standard test: a summary of Dutch experience, 1989-94. Allergy 50:234-242

Pinder RM, van Delft AM (1983) Pharmacological aspects of mianserin. Acta Psychiatr Scand Suppl 302:59-71

Radhakishun FS, van den Bos J, van der Heijden BC, Roes KC, O'Hanlon JF (2000) Mirtazapine effects on alertness and sleep in patients as recorded by interactive telecommunication during treatment with different dosing regimens. J Clin Psychopharmacol 20:531-537

Ramaekers JG (2003) Antidepressants and driver impairment: empirical evidence from a standard on-the-road test. J Clin Psychiatry 64:20-29 
Ramaekers JG, Kauert G, van Ruitenbeek P, Theunissen EL, Schneider E, Moeller MR (2006) High-potency marijuana impairs executive function and inhibitory motor control. Neuropsychopharmacology 31:2296-2303

Ramaekers JG, Kuypers KP (2006) Acute effects of 3, 4methylenedioxymethamphetamine (MDMA) on behavioral measures of impulsivity: alone and in combination with alcohol. Neuropsychopharmacology 31:1048-1055

Ramaekers JG, Muntjewerff ND, Van Veggel LMA, Uiterwijk MMC, O'Hanlon JF (1998) Effects of nocturnal doses of mirtazapine and mianserin on sleep and on daytime psychomotor and driving performance of healthy volunteers. Hum Psychopharmacol 13: S87-S97

Ramaekers JG, Swijgman HF, O'Hanlon JF (1992) Effects of moclobemide and mianserin on highway driving, psychometric performance and subjective parameters, relative to placebo. Psychopharmacology (Berl) 106 Suppl:S62-S67

Ridout F, Meadows R, Johnsen S, Hindmarch I (2003) A placebo controlled investigation into the effects of paroxetine and mirtazapine on measures related to car driving performance. Hum Psychopharmacol 18:261-269

Ruigt GS, Kemp B, Groenhout CM, Kamphuisen HA (1990) Effect of the antidepressant Org 3770 on human sleep. Eur J Clin Pharmacol 38:551-554

Schmid DA, Wichniak A, Uhr M, Ising M, Brunner H, Held K, Weikel JC, Sonntag A, Steiger A (2006) Changes of sleep architecture, spectral composition of sleep EEG, the nocturnal secretion of cortisol, ACTH, GH, prolactin, melatonin, ghrelin, and leptin, and the DEX-CRH test in depressed patients during treatment with mirtazapine. Neuropsychopharmacology 31:832844

Stahl SM (2008) Selective histamine H1 antagonism: novel hypnotic and pharmacologic actions challenge classical notions of antihistamines. CNS Spectr 13:1027-1038

Tomalik-Scharte D, Lazar A, Fuhr U, Kirchheiner J (2008) The clinical role of genetic polymorphisms in drug-metabolizing enzymes. Pharmacogenomics J 8:4-15

van Laar M, Volkerts E, Verbaten M (2001) Subchronic effects of the GABA-agonist lorazepam and the 5-HT2A/2 C antagonist ritanserin on driving performance, slow wave sleep and daytime sleepiness in healthy volunteers. Psychopharmacology (Berl) 154:189-197

Vermeeren A (2004) Residual effects of hypnotics: epidemiology and clinical implications. CNS Drugs 18:297-328

Wingen M, Bothmer J, Langer S, Ramaekers JG (2005) Actual driving performance and psychomotor function in healthy subjects after acute and subchronic treatment with escitalopram, mirtazapine, and placebo: a crossover trial. J Clin Psychiatry 66:436-443

Wingen M, Langer S, Ramaekers JG (2006) Verbal memory performance during subchronic challenge with a selective serotonergic and a mixed action antidepressant. Hum Psychopharmacol 21:473-479

Winokur A, Sateia MJ, Hayes JB, Bayles-Dazet W, MacDonald MM, Gary KA (2000) Acute effects of mirtazapine on sleep continuity and sleep architecture in depressed patients: a pilot study. Biol Psychiatry 48:75-78 